\title{
In vitro mitomycin $C$ absorption and delivery with different sponge materials used in filtering surgery
}

\author{
This article was published in the following Dove Press journal: \\ Clinical Ophthalmology \\ 15 April 2016 \\ Number of times this article has been viewed
}

Diana Urbaneja'
Antonio Morilla-Grasa'
Elisa Jimenez'
Judith Montemayor'
Nuria Marcobal'
Carme Aragay ${ }^{2}$
Celia Gurdiel ${ }^{2}$
Marta Armillas ${ }^{2}$
Pere Ortiz ${ }^{2}$
Alfonso Antón ${ }^{1-3}$
'Department of Ophthalmology,
Institut Català de Retina, Barcelona,
Spain; ${ }^{2}$ Department of Ophthalmology,
Hospital Ntra Sra De La Esperanza -
Parc de Salut Mar, Barcelona,
Spain; ${ }^{3}$ Universitat Internacional de
Catalunya, Barcelona, Spain

Catalunya, Barcelona, Spain
Purpose: The purpose of this study is to evaluate and compare mitomycin C (MMC) absorption and delivery in different materials used in filtering surgery.

Methods: This is an in vitro study comparing polyvinyl alcohol triangular sponges (TS6, TS8), polyvinyl alcohol fluid wicks (EFW), and absorbable gelatin sponges (AGS3, AGS5), from which five different types of transport units were obtained. Seven pieces of sponge of each transport unit type were obtained as follows: two transverse strips were obtained at 6 and $8 \mathrm{~mm}$ from the apex of TS and divided into three equal pieces; $4 \times 4 \mathrm{~mm}$ pieces of $\mathrm{EFW} ; 3 \times 3$ and $5 \times 5 \mathrm{~mm}$ pieces of absorbable gelatin sponges were cut. Filter paper was placed on a precision scale $(0.01 \mathrm{mg})$. The seven sponge pieces of each type were weighed three times consecutively in dry and wet states, the latter after immersion for 15 seconds in $0.2 \mathrm{mg} / \mathrm{mL} \mathrm{MMC}$. The difference between the weights of the dry and wet filter paper at the end of each measurement sequence was also calculated and considered as an estimate of the amount of mitomycin delivered.

Results: The amounts of MMC absorbed by each transport unit were as follows: (mean \pm standard deviation) $27.43 \pm 5.13$ for TS6, $31.91 \pm 6.63$ for TS8, $15.96 \pm 2.23$ for EFW, 17.96 \pm 2.05 for AGS3, and 33.81 \pm 2.05 for AGS5. The amounts of MMC delivered to the filter paper were as follows: $21.70 \pm 2.84$ for TS6, $23.83 \pm 4.03$ for TS8, $12.93 \pm 1.75$ for EFW, $14.69 \pm 1.79$ for AGS3, and 27.30 \pm 1.58 for AGS5.

Conclusion: Percentage MMC delivered was similar for all materials, but there was a tendency for greater delivery using larger sponges and greater homogeneity in delivery with AGS5. No statistical differences were found in percentage delivered by the different transport materials.

Keywords: glaucoma, absorbable gelatin sponges, mitomycin, polyvinyl alcohol

\section{Introduction}

The use of antimitotic substances such as mitomycin C (MMC) is common in glaucoma surgery for the prevention of scarring at the subconjunctival space. MMC has been demonstrated to improve surgical outcomes, ${ }^{1,2}$ and its efficacy depends primarily on the concentration and volume used for intraoperative application. ${ }^{3,4}$ However, this improvement in surgical success with adjunctive use of intraoperative MMC increases the risk of postoperative complications such as wound or bleb leaks, hypotony, cataracts, and hypotony maculopathy. ${ }^{5-8}$ For this reason, it is of crucial importance to standardize the amount of mitomycin applied in order to make it more homogenous between surgeries and so reduce said complications.

In a standard trabeculectomy technique, pieces of microsurgical sponges of different brands and sizes previously soaked in an MMC solution are placed on the sclera at concentrations from 0.2 to $0.5 \mathrm{mg} / \mathrm{mL}$. They remain under the conjunctiva for 1-5 minutes, after which they are removed, followed by copious irrigation with balanced salt solution. Many different commercially available materials have been used for this
Correspondence: Diana Urbaneja Department of Ophthalmology, Institut Català de Retina, Carrer Ganduxer II7, 08022 Barcelona, Spain

Tel +34 679376950

Email dianau3000@gmail.com
Clinical Ophthalmology 2016:10 665-669

(c) (7) (을 2016 Urbaneja et al. This work is published and licensed by Dove Medical Press Limited. The full terms of this license are available at https://www.dovepress.com/terms.php cc. ${ }_{\mathrm{BY}} \mathrm{NC}$ and incorporate the Creative Commons Attribution - Non Commercial (unported, v3.0) License (http://creativecommons.org/licenses/by-nc/3.0/). By accessing the work you hereby accept the Terms. Non-commercial uses of the work are permitted without any further permission from Dove Medical Press Limited, provided the work is properly attributed. For permission
for commercial use of this work, please see paragraphs 4.2 and 5 of our Terms (https://www.dovepress.com/terms.php). 
purpose, including polyvinyl alcohol (PVA), methylcellulose, and absorbable gelatin sponges (AGSs). ${ }^{9,10}$

Once filtration surgery is performed, the key determining factors of intraocular pressure control are the formation of a filtering bleb or intrascleral lake in relation to the scarring process. In this regard, new imaging devices, such as anterior segment optical coherence tomography, have helped to identify signs of functioning and nonfunctioning filtering blebs by noninvasive methods. ${ }^{11-13}$ Furthermore, such technology could possibly be used to study drug delivery issues in vivo (eg, intraoperatively).

Previously published data on drug delivery kinetics have suggested that the amounts of antifibrotic agent absorbed and released could vary considerably among materials. ${ }^{14}$ However, most of the absorption and delivery processes have been carried out in vitro between brands of polyvinyl and methylcellulose sponges. ${ }^{15}$ To our knowledge, there are no previous studies comparing AGSs with other types of materials.

Gelatin is a material derived from the hydrolysis of collagen from a variety of animals (most commonly porcine, fish, and bovine), which is utilized in ophthalmology due to several advantages, including its biocompatible nature as well as its low-cost commercial availability. ${ }^{16,17}$ In addition, gelatin has been reported to decrease the antigenic response in vivo compared to collagen, since it contains smaller quantities of tyrosine, tryptophan, and phenylalanine. ${ }^{18}$

On the other hand, PVA is also a biocompatible synthetic polymer obtained from partial or full hydrolysis of polyvinyl acetate. It has low protein absorption, which results in lower cell adhesion, compared with other hydrogels. Furthermore, it is used in implantable devices, indicating that it is safe for human use in applications where absorption of host proteins would be undesired. ${ }^{19}$

Many studies have concluded that gelatin-containing materials decrease levels of blood loss during surgery ${ }^{20}$ and perform better during different artery embolization procedures, compared to PVA materials. ${ }^{21,22}$ These results might be explained by a lower immune response of the host to gelatin materials, in which case, the use of gelatin materials could further benefit the formation of a functioning filtering bleb.

The purpose of this study was to evaluate and compare the amount of MMC absorbed and delivered by PVA sponges and AGSs used in glaucoma surgery.

\section{Materials and methods Design}

This is an in vitro study performed at the Institut Català de Retina and Hospital Ntra. Sra. De la Esperanza - Parc de Salut Mar, Barcelona, Spain.

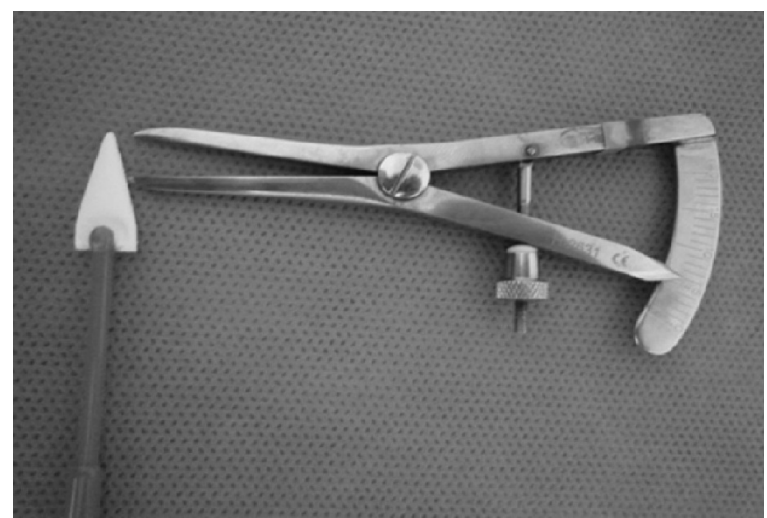

Figure I Polyvinyl alcohol sponge and compass used to measure 6 and $8 \mathrm{~mm}$ from the tip, to create TS6 and TS8, respectively.

\section{Materials}

Three types of transport materials were used. Five different types of transport units were obtained from them:

- PVA triangular sponges (with two fragmentation techniques).

- PVA fluid wicks (EFW: $4 \times 4 \mathrm{~mm}$ ).

- AGSs (AGS3: $3 \times 3 \mathrm{~mm}$ and AGS5: $5 \times 5 \mathrm{~mm}$ ).

\section{Preparation of materials}

Different fragmentation methods were used for each type of material, based on what was used by different glaucoma specialists in our environment. For the PVA triangular sponges, a surgical compass was used to measure 6 and $7 \mathrm{~mm}$ (TS6) from the tip of the sponge. Then, one strip of material was obtained with two perpendicular cuts with sharp scissors. Finally, the strip was cut into three similarly sized pieces. The procedure was repeated at 8 and $9 \mathrm{~mm}$ from the apex to obtain transport unit type TS8 (Figures 1 and 2). For EFW, a compass was used to measure and mark $4 \times 4 \mathrm{~mm}$ and then

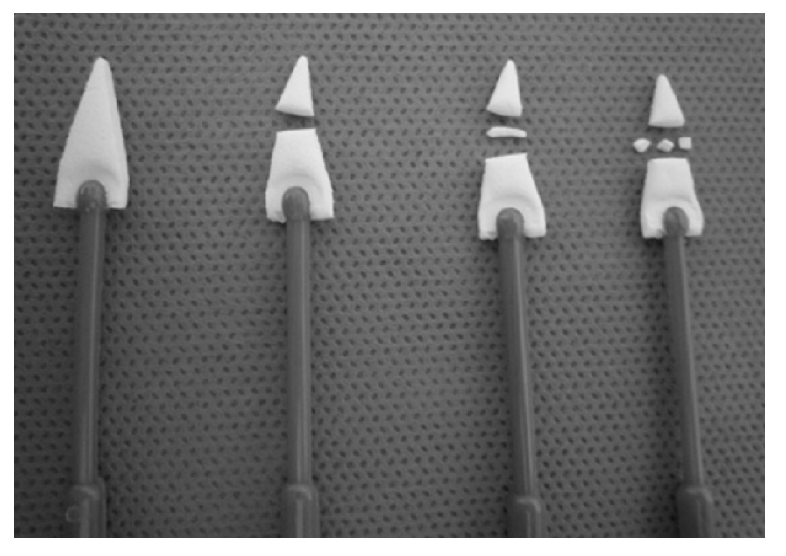

Figure 2 Fragmentation method for polyvinyl alcohol sponges.

Notes: Measurements at 6 and $7 \mathrm{~mm}$ (TS6) from the tip of the spear were made to obtain a strip, which was subsequently fragmented into three pieces of similar size. The procedure was repeated at 8 and $9 \mathrm{~mm}$ from the apex (TS8). 


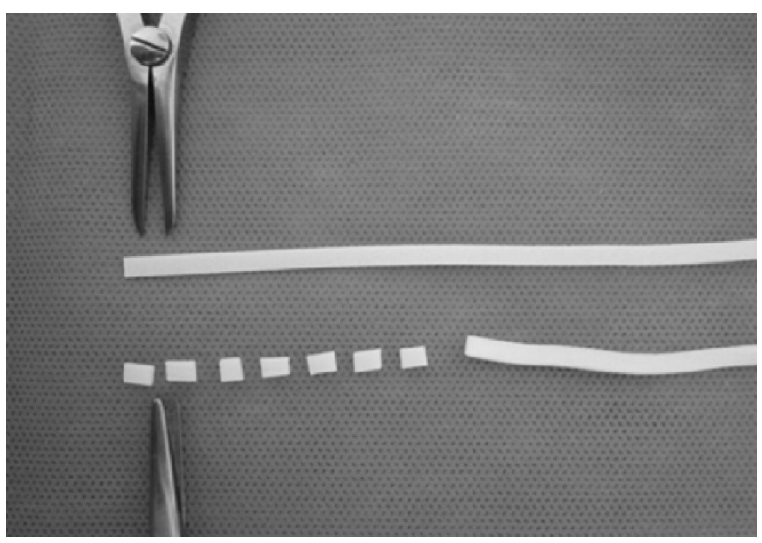

Figure 3 Fragmentation method for polyvinyl alcohol fluid wick.

Note: Pieces of $4 \times 4 \mathrm{~mm}$ were obtained by end marks made with a compass.

surgical scissors was used to cut (Figure 3). AGSs were cut into $3 \times 3 \mathrm{~mm}$ (AGS3) and $5 \times 5 \mathrm{~mm}$ (AGS5) pieces (Figure 4). To calculate homogeneity within applications, seven equal pieces of each transport unit type were obtained and placed in a transparent Petri dish and numbered from 1 to 7 . A precision scale (Sartorius TE214S; readability: $0.1 \mathrm{mg}$, sensitivity drift: $\pm 2 \times 10^{-6}\left[+10^{\circ} \mathrm{C}\right.$ to $\left.+30^{\circ} \mathrm{C}\right]$, and reproducibility [standard deviation]: $\pm 0.1 \mathrm{mg}$ ) was used for weighing.

\section{Weighing procedure}

The scale was calibrated, and then the filter paper was weighed. Next, the scale was zeroed. Following this step, each piece of each transport unit was placed on the filter paper, and its dry weight was measured. This process was repeated three times to calculate the mean weight for each piece. A new dry filter paper was used for each piece (seven for each transport unit type).

Each piece of material was placed in a Petri dish containing MMC $(0.2 \mathrm{mg} / \mathrm{mL})$ for 15 seconds. Then, one piece at a time was removed and placed back onto the same filter paper

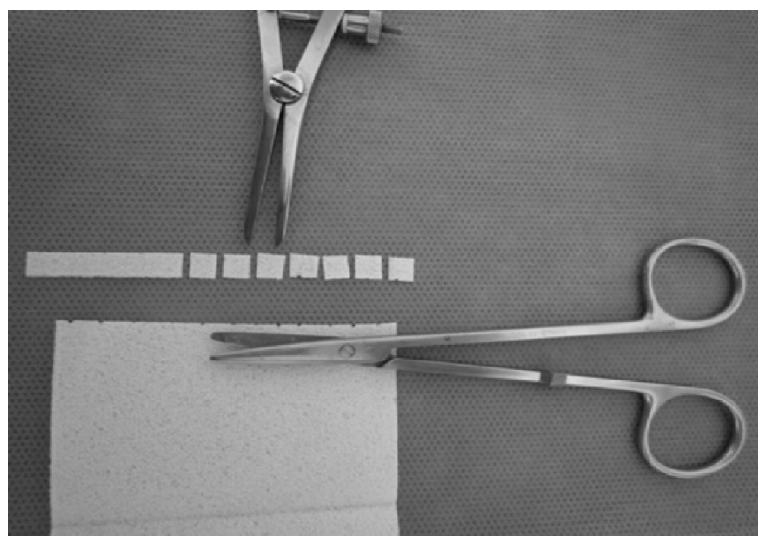

Figure 4 Absorbable gelatin sponges.

Note: $A$ compass was used to create $3 \times 3$ (AGS3) and $5 \times 5 \mathrm{~mm}$ (AGS5) sponge pieces. on the previously zeroed scale. This step was repeated three times for each piece of material, by lifting off and replacing it back on the filter paper. The amount of MMC absorbed was defined as the weight added on each piece of material after being soaked in the MMC solution. The amount of MMC delivered was estimated by calculating the difference between the weights of the mean dry and wet filter paper.

\section{Statistical methods}

To calculate the sample size, we used data from Alcon Laboratories, Inc., Fort Worth, TX, USA sponges reported in a previous article published by Flynn et al. ${ }^{15} \mathrm{~A}$ level of confidence of $95 \%$ and a level of precision of $6 \%$ were defined.

Analysis of variance and Schéffé post hoc test analyses were performed using SPSS version 22.0 (IBM Corporation, Armonk, NY, USA), comparing differences in the percentage of MMC delivered by the different transport unit types. The coefficient of variation was used to evaluate the variability of MMC absorbed and delivered by each sponge type.

\section{Results}

Mean dry sponge weight per transport unit type $(\mathrm{mg})$ was as follows: $2.62 \pm 0.55$ for TS $6 \mathrm{~mm}, 3.04 \pm 0.78$ for TS $8 \mathrm{~mm}, 1.68 \pm 0.14$ for EFW, $0.90 \pm 0.31$ for AGS $3 \times 3 \mathrm{~mm}$, and $1.47 \pm 0.12$ for AGS $5 \times 5 \mathrm{~mm}$. The amounts of MMC absorbed and delivered are shown in Table 1 and Figure 5. No statistically significant differences were found between the sponges in the percentage of MMC delivered $(P=0.234)$. However, significant differences were found in the amount of MMC delivered, as larger sponges (TS6, TS8, and AGS5) delivered more MMC than smaller sponges (EFW, AGS3) $(P<0.001)$.

\section{Discussion}

To date, there is no gold standard method for the application of MMC on the sclera during filtering surgery. Different techniques have been described and investigated, with important variations in duration of exposure, concentration, and delivery system used. All these factors seem to influence bleb appearance and mean intraocular pressure achieved after surgery. ${ }^{15}$

This study compared three different brands of two transport materials (PVA and absorbable gelatin) frequently used by glaucoma specialists, in order to estimate the amount of MMC delivered to the filtering site. Methylcellulose sponges were not included in this study. They are not used in our center, since in our experience, they tend to fragment when left on the surgical site. Furthermore, some cases of foreign 
Table I Amounts of MMC absorbed and delivered to the filter paper

\begin{tabular}{lllll}
\hline $\begin{array}{l}\text { Sponge } \\
\text { type }\end{array}$ & $\begin{array}{l}\text { MMC absorbed } \\
(\mathbf{m g})\end{array}$ & $\begin{array}{l}\text { MMC delivered } \\
\text { to filter }(\mathbf{m g})\end{array}$ & $\begin{array}{l}\text { Coefficient of variation } \\
\text { of MMC delivered }\end{array}$ & $\begin{array}{l}\text { Percentage of MMC } \\
\text { delivered to the filter }\end{array}$ \\
\hline TS6 & $27.43 \pm 5.13$ & $21.70 \pm 2.84$ & 0.13 & 80 \\
TS8 & $31.91 \pm 6.63$ & $23.83 \pm 4.03$ & 0.16 & 75 \\
EFW & $15.96 \pm 2.23$ & $12.93 \pm 1.75$ & 0.13 & 81 \\
AGS3 & $17.96 \pm 2.05$ & $14.69 \pm 1.79$ & 0.11 & 82 \\
AGS5 & $33.81 \pm 2.05$ & $27.30 \pm 1.58$ & 0.05 & 81 \\
\hline
\end{tabular}

Notes: TS6: polyvinyl triangle sponges cut at $6 \mathrm{~mm}$ from the tip; TS8: polyvinyl triangle sponges cut at $8 \mathrm{~mm}$ from the tip; EFW: polyvinyl fluid wicks $4 \times 4$ mm; AGS3: absorbable gelatin sponges $3 \times 3 \mathrm{~mm}$; AGS5: absorbable gelatin sponges $5 \times 5 \mathrm{~mm}$. Data are presented as mean \pm standard deviation.

Abbreviation: MMC, mitomycin C.

body reactions have been reported due to fragmentation of cellulose sponges. ${ }^{5,23}$

Our results indicate that the percentage of MMC delivered was similar for all transport unit types, in spite of their different sizes and materials $(75 \%-80 \%)$. These results contrast with those found by Yamamoto and Kitazawa, ${ }^{24}$ who measured the amount of drug remaining in sponges used after trabeculectomy with high-performance liquid chromatography. In their study, only an average of $16.8 \%$ of the total dose seeped out from their sponges. ${ }^{24}$ This significant difference in percentage of MMC delivered could be due to two main reasons: First, the sponge material used by Yamamoto and Kitazawa was not specified, and it could be an important factor in the difference in doses of MMC delivered. ${ }^{15}$ Second, the method used to take measurements was also different across the two studies. While Yamamoto and Kitazawa used high-performance liquid chromatography, a precise method to separate and quantify chemical components in a mixture, we estimated the amount of MMC

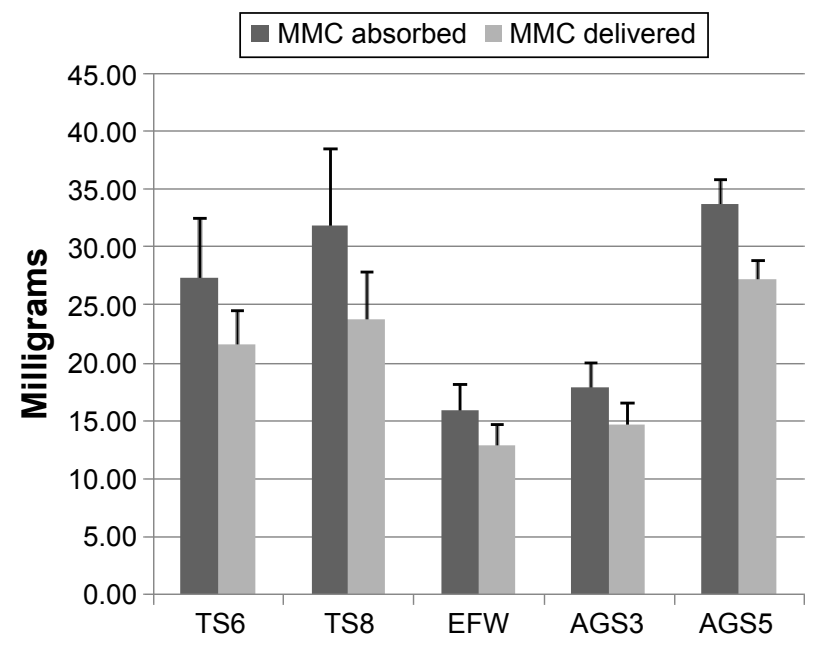

Figure 5 Amount of MMC absorbed and delivered to the filter paper (mg). Note: TS6: polyvinyl triangle sponges cut at $6 \mathrm{~mm}$ from the tip; TS8: polyvinyl triangle sponges cut at $8 \mathrm{~mm}$ from the tip; EFW: polyvinyl fluid wicks $4 \times 4 \mathrm{~mm}$; AGS: absorbable gelatin sponges $3 \times 3 \mathrm{~mm}$; AGS5: absorbable gelatin sponges $5 \times 5 \mathrm{~mm}$. Abbreviation: MMC, mitomycin C. delivered by subtracting the weight of the dry filter paper from that of the wet filter paper. In addition, better potential absorption of dry filter paper compared to scleral and conjunctival tissue could also be a major factor involved in these differences.

Our findings also showed that the weight of MMC solution delivered to the filter paper was greater for larger sponges, supporting the results of previous studies. ${ }^{15,25,26}$ Larger sponges absorb more MMC that can be delivered to the surgical site. This issue should be taken into account when making clinical decisions on exposure and concentration of MMC, to maximize its therapeutic effect while minimizing the dose. ${ }^{24}$

Another important finding of this study was that some material unit types behaved more homogenously or reproducibly than others. The $5 \mathrm{~mm}$ AGSs (AGS5) seemed to release the most reproducible amount of MMC solution each time, followed by $3 \mathrm{~mm}$ absorbable gelatin (AGS3) and the remaining transport materials. Therefore, our results suggest that using this type of material could help to reduce considerably variations in drug delivery to the surgical site. This could be clinically relevant in the immediate and/or the late postoperative phase.

This study had some limitations. First, our model did not evaluate time in the kinetics of drug delivery for PVA sponges and AGSs, which is another key element that might play a role in final surgical outcomes. Brooks et al reported that methylcellulose sponges delivered MMC in a nonlinear fashion, so that rapid delivery occurs within the first 15-30 seconds, followed by a slow delivery phase that extends up to a 5-minute period. ${ }^{25}$ Also, Larrosa et al, ${ }^{26}$ who used AGSs, concluded that $25 \%$ of the drug is delivered to the surrounding tissues in the first minute. Second, our method for estimating the amount of MMC solution delivered is rather rudimentary, and can only estimate what might occur on human tissue during surgery. Despite these limitations, we believe that our study adds some significant knowledge 
to the limited evidence on MMC management in glaucoma surgery.

In summary, according to our results, the size and material used for drug transportation and delivery have a major impact on the amount of MMC applied in vitro. The larger the sponge size, the greater the amount of MMC solution delivered to the surgical site. Moreover, AGSs seem to deliver a more reproducible weight of drug solution. The use of a more standardized method and material (type and size) in trabeculectomy-related research could help to increase homogeneity of surgical results and safety. Further studies on transport materials are required to increase the evidence on this issue as well as to increase safety and efficacy of glaucoma filtering surgery. Noninvasive technologies such as anterior segment optical coherence tomography might be helpful to evaluate these aspects in vivo.

\section{Disclosure}

The authors report no conflicts of interest in this work.

\section{References}

1. European Glaucoma Society, editor. Terminology and Guidelines for Glaucoma. 4th ed. Savona: PubliComm; 2014.

2. Khaw PT, Sherwood MB, MacKay SL, Rossi MJ, Schultz G. Five-minute treatments with fluorouracil, floxuridine, and mitomycin have longterm effects on human Tenon's capsule fibroblasts. Arch Ophthalmol. 1992;110(8):1150-1154.

3. Sari A, Onol M, Ozdek S, Ozogul C, Hasanreisoglu B. Effect of mitomycin $\mathrm{C}$ on ciliary body and intraocular pressure with various application depths: an experimental study. Clin Experiment Ophthalmol. 2005;33(2):169-175.

4. Hitchings RA, Grierson I. Clinico pathological correlation in eyes with failed fistulizing surgery. Trans Ophthalmol Soc U K. 1983;103(Pt 1): $84-88$.

5. Shin DH, Tsai CS, Kupin TH, Olivier MM. Retained cellulose sponge after trabeculectomy with adjunctive subconjunctival mitomycin C. Am J Ophthalmol. 1994;118(1):111-112.

6. Seibold LK, Sherwood MB, Kahook MY. Wound modulation after filtration surgery. Surv Ophthalmol. 2012;57(6):530-550.

7. Holló G. Wound healing and glaucoma surgery: modulating the scarring process with conventional antimetabolites and new molecules. Dev Ophthalmol. 2012;50:79-89.

8. Singh K, Mehta K, Shaikh NM, et al. Trabeculectomy with intraoperative mitomycin $\mathrm{C}$ versus 5-fluorouracil. Prospective randomized clinical trial. Ophthalmology. 2000;107(12):2305-2309.

9. Jones E, Clarke J, Khaw PT. Recent advances in trabeculectomy technique. Curr Opin Ophthalmol. 2005;16(2):107-113.

Clinical Ophthalmology

\section{Publish your work in this journal}

Clinical Ophthalmology is an international, peer-reviewed journal covering all subspecialties within ophthalmology. Key topics include: Optometry; Visual science; Pharmacology and drug therapy in eye diseases; Basic Sciences; Primary and Secondary eye care; Patient Safety and Quality of Care Improvements. This journal is indexed on Submit your manuscript here: http://www.dovepress.com/clinical-ophthalmology-journal
10. Anand N, Arora S, Clowes M. Mitomycin C augmented glaucoma surgery: evolution of filtering bleb avascularity, transconjunctival oozing, and leaks. Br J Ophthalmol. 2006;90(2):175-180.

11. Mastropasqua R, Fasanella V, Agnifili L, Curcio C, Ciancaglini M, Mastropasqua L. Anterior segment optical coherence tomography imaging of conjunctival filtering blebs after glaucoma surgery. BioMed Res Int. 2014;2014:610623.

12. Hirooka K, Takagishi M, Baba T, Takenaka H, Shiraga F. Stratus optical coherence tomography study of filtering blebs after primary trabeculectomy with a fornix-based conjunctival flap. Acta Ophthalmol (Copenh). 2010;88(1):60-64.

13. Napoli PE, Zucca I, Fossarello M. Qualitative and quantitative analysis of filtering blebs with optical coherence tomography. Can J Ophthalmol. 2014;49(2):210-216.

14. Mehel E, Weber M, Stork L, Péchereau A. A novel method for controlling the quantity of mitomycin-C applied during filtering surgery for glaucoma. J Ocul Pharmacol Ther. 1998;14(6):491-496.

15. Flynn WJ, Carlson DW, Bifano SL. Mitomycin trabeculectomy: the microsurgical sponge difference. J Glaucoma. 1995;4(2):86-90.

16. Jones RT. Gelatin: manufacture and physio-chemical properties. In: Pharmaceutical Capsules. London, UK: Pharm Press; 2004;23-60.

17. Rose JB, Pacelli S, El Haj AJ, et al. Gelatin-based materials in ocular tissue engineering. Materials. 2014;7(4):3106-3135.

18. Lynn AK, Yannas IV, Bonfield W. Antigenicity and immunogenicity of collagen. J Biomed Mater Res B Appl Biomater. 2004;71(2):343-354.

19. Baker MI, Walsh SP, Schwartz Z, Boyan BD. A review of polyvinyl alcohol and its uses in cartilage and orthopedic applications. J Biomed Mater Res B Appl Biomater. 2012;100(5):1451-1457.

20. Bendszus M, Klein R, Burger R, Warmuth-Metz M, Hofmann E, Solymosi L. Efficacy of trisacryl gelatin microspheres versus polyvinyl alcohol particles in the preoperative embolization of meningiomas. AJNR Am J Neuroradiol. 2000;21(2):255-261.

21. Song YG, Jang H, Park KD, Kim MD, Kim C-W. Non spherical polyvinyl alcohol versus gelatin sponge particles for uterine artery embolization for symptomatic fibroids. Minim Invasive Ther Allied Technol. 2013;22(6):364-371.

22. Spies JB, Allison S, Flick P, et al. Spherical polyvinyl alcohol versus tris-acryl gelatin microspheres for uterine artery embolization for leiomyomas: results of a limited randomized comparative study. $J$ Vasc Interv Radiol. 2005;16(11):1431-1437.

23. Poole TRG, Gillespie IH, Knee G, Whitworth J. Microscopic fragmentation of ophthalmic surgical sponge spears used for delivery of antiproliferative agents in glaucoma filtering surgery. Br J Ophthalmol. 2002;86(12):1448-1449.

24. Yamamoto T, Kitazawa Y. Residual mitomycin C dosage in surgical sponges removed at the time of trabeculectomy. Am J Ophthalmol. 1994;117(5):672-673.

25. Brooks SE, Laird ML, Marcus DM, Johnson MH, Ramage JI, Green K. Kinetics of fluid delivery from methylcellulose sponges. J Glaucoma. 1998; 7(1):16-21.

26. Larrosa JM, Polo V, Pinilla I, et al. Quantification of intraoperative administration of mitomycin-C in filtering surgery with surgical sponge material. J Glaucoma. 1999;8(1):46-50.

PubMed Central and CAS, and is the official journal of The Society of Clinical Ophthalmology (SCO). The manuscript management system is completely online and includes a very quick and fair peer-review system, which is all easy to use. Visit http://www.dovepress.com/ testimonials.php to read real quotes from published authors. 